\title{
REVIEW
}

\section{Proteomic and metabolomic strategies to investigate HIV-associated neurocognitive disorders}

\author{
Gurudutt Pendyala and Howard S Fox*
}

\begin{abstract}
Diagnosing neurodegenerative diseases, monitoring their progression and assessing responses to treatments will all be aided by the identification of molecular markers of different stages of pathology. Protein biomarkers for HIV-associated neurocognitive disorders that have been discovered using proteomics include complement C3, soluble superoxide dismutase and a prostaglandin synthase. Metabolomics has not yet been widely used for biomarker discovery, but early work shows that it has great potential.
\end{abstract}

\section{Background}

Human immunodeficiency virus (HIV) is a lentivirus that targets $\mathrm{CD} 4^{+}$cells in vivo, including a subset of lymphocytes $\left(\mathrm{CD} 4^{+} \mathrm{T}\right.$ cells) and a broad range of mononuclear phagocytes, including monocytes, dendritic cells, tissue macrophages and brain microglia. The destruction of $\mathrm{CD}^{+} \mathrm{T}$ cells and immune dysfunction results in a progressive immunodeficiency called acquired immunodeficiency syndrome (AIDS), which in the absence of treatment leads to opportunistic infections and malignancies [1]. Although immune system disorders have been focused on the most, HIV infection also has significant effects on the central nervous system (CNS), as the virus both infects and affects the brain [2]. The associated neuropsychopathology or CNS dysfunction then leads to a group of cognitive and behavioral changes now termed HIV-1-associated neurocognitive disorders (HAND) or neuroAIDS. NeuroAIDS encompasses a broad range of neurological abnormalities, including asymptomatic neurocognitive impairment, HIV-associated mild

\footnotetext{
*Correspondence: hfox@unmc.edu
}

Department of Pharmacology and Experimental Neuroscience, University of Nebraska Medical Center, 985800 Nebraska Medical Center, Omaha, NE 68198, USA cognitive motor disorder and the most severe disease, HIV-1-associated dementia (HAD) [3].

The advent of combined antiretroviral therapy (cART; previously referred to as highly active antiretroviral therapy, HAART), however, has significantly changed the dynamics of HIV neuropathogenesis [4]. Severe dementia now affects less than $7 \%$ of infected people during the latter stages of disease. Because of the increasing longevity of HIV-1-infected individuals, the incidence of HAD, as well as the other cognitive and motor abnormalities associated with HIV-1 infection, has declined, although the overall prevalence of neuroAIDS has increased [1,3,5-7]. The most severe cognitive, motor and behavioral impairments are now supplanted by milder, less profound cognitive impairment that can nevertheless cause significant problems in individuals' daily lives [8]. HIV-related CNS disease is no longer a result of continuous productive viral infection and activation of brain macrophages and microglia, but rather a result of more limited infection and neuroinflammation [9]. Although widespread use of cART in places where resources are sufficient has increased life expectancy for virus-infected individuals, with a concomitant decrease in disease morbidities [10,11], neurological complications continue to persist. This may be attributed to viral mutation and cART resistance, failure of drugs to access viral sanctuaries, toxicities of cART and poor compliance to complex cART regimens [12-15]. Abuse of illegal drugs [16] and lack of cART availability [17] may also influence neurological disease manifestations. Many aspects of neuroAIDS pathogenesis are well covered in recent reviews $[18,19]$.

Early in the course of infection, HIV enters the CNS and remains detectable throughout the course of infection. Although HIV does not infect neurons, it attacks the monocytic lineage in the brain: macrophages and microglia [20-23]. The neurotoxicity arising from HIV infection therefore results from an indirect mechanism, possibly involving toxic viral proteins or inflammatory mediators produced by activated macrophages and microglia [24-28], as well as the adaptive immune 
response to the virus in the brain [29,30]. Although studies on the brain can be problematic in humans, an excellent animal model, simian immunodeficiency virus (SIV) infection of nonhuman primates, recapitulates well many aspects of HIV pathogenesis, including neuroAIDS [31-35].

A critical gap in the field of neuroAIDS research is the identification of reliable molecular markers; these could provide valuable insights into the mechanisms of neuropathogenesis and response to therapies, and they could aid in the prediction of development of disease. Biomarkers are biological parameters that are objectively measured and quantifiable and that indicate changes in physiological states due to pathogenic processes or therapeutic intervention. In addition to being invaluable clinically, they have an increasingly prominent role in drug development and medical research $[36,37]$.

Despite substantive research efforts, the mechanisms underlying cognitive impairment resulting from HIV infection are far from understood. However, the advent of high-throughput strategies such as genomics, transcriptomics, proteomics and metabolomics has revolutionized biological investigations and brought great insights. This especially holds true for mass spectrometry (MS)-based proteomics and metabolomics, which have generated immense interest and which offer different but complementary insights into the full complexity of the disease phenotype. In addition to allowing the unbiased identification of molecular markers for disease states, these approaches also enable a greater understanding of the processes underlying them.

\section{Neuroproteomics and biofluids profiling Cerebrospinal fluid biomarkers for neuroAIDS}

Neuroproteomics reveals complex protein expression, function, interactions and localization in cells of the nervous system. Although ideally one would analyze the brain itself, obtaining brain biopsy specimens is not usually practical. Profiling of biofluids is therefore ideal, and the relative ease of obtaining data from the same animals or people over time also means that longitudinal molecular analyses of changes during the course of neurological diseases can be conducted. Of the biofluids, the cerebrospinal fluid (CSF) is close to the site of neuropathology and can reflect the biochemical milieu of the CNS. There is a growing consensus that the CSF is the best material for biomarker discovery and for understanding the ongoing pathological processes associated with neurodegeneration $[38,39]$. The protein component of CSF consists of brain-derived proteins as well as many proteins that are also abundant in plasma [40]. The complexity and great dynamic range of protein concentrations as well as protein heterogeneity in the CSF create significant challenges to the existing proteomic technologies [41]. To address these challenges (which are not unique for CSF and also apply to blood-based tests on plasma and serum), advances have been made on two fronts: enrichment of potential proteins of interest expressed at lower levels by immunodepletion of abundant proteins [42], and an improved ability to separate the great number of peptides resulting from protein digestion using multi-dimensional chromatography before MS [43].

One recent study used immunodepletion followed by two-dimensional difference gel electrophoresis (2D-DIGE) to identify differentially expressed features and then MS to identify the proteins that differentiated individuals with HAD from HIV-infected individuals without CNS disease [44]. This method required a certain amount of protein, because of which only 6 of the 38 available samples (16\%) could be assessed. Nevertheless, this study was successful in identifying six putative biomarkers: vitamin D binding protein, clusterin, gelsolin, complement $\mathrm{C} 3$, procollagen $\mathrm{C}$-endopeptidase enhancer 1 and cystatin C. Of these, vitamin D binding protein was upregulated and the other five proteins were downregulated in the CSF of HAD patients.

A separate study from our lab [45] used a more streamlined approach to identify differentially expressed proteins in the CSF of SIV-infected monkeys, comparing the CSF from the same animals before infection and during CNS disease. This technique bypassed immunodepletion or other manipulations and used small amounts of protein isolated by organic extraction followed by limited pre-fractionation using a liquid chromatography tandem MS (LC-MS/MS) approach. Among the proteins differentially expressed in the SIV-infected monkeys, complement C3 was identified but found to be upregulated in the CSF of infected monkeys. The difference between the two studies $[44,45]$ can be attributed to numerous factors, including looking at a human disease or a monkey model, the different sites of CSF removal, the study designs and other aspects of experimentation.

We also investigated [45] whether the increase in C3 reflected synthesis in the brain or leakage across the blood-brain barrier. Quantitative real-time PCR revealed that the mRNA level of C3 was indeed increased in the brains of diseased animals. This increase corroborates other studies in which an increase in C3 in astrocytes, microglia and, to a lesser extent, neurons was found in SIV encephalitis (SIVE) [46]. Furthermore, increased C3 has been found in other human CNS disorders, including Alzheimer's disease and multiple sclerosis [47]. The enhanced complement synthesis may reflect immune activation in the brain, leading to the formation of molecules such as the anaphylatoxins C3a and C5a, which act as chemoattractants and activators of macrophages and microglia and may act through these cells or 
other mechanisms to protect [48-50] or damage [51-54] the brain. Thus, in the case of SIVE, increased C3 probably contributes to SIV-induced damage to the brain.

Two studies have used surface enhanced laser desorption ionization (SELDI) to examine the CSF. In one, nine proteins were identified uniquely in the CSF of individuals with $\mathrm{HIV}$-associated cognitive impairment [55]. These included soluble superoxide dismutase (SOD1), for which western blot analysis verified its increase. SOD1 is an antioxidant and migration inhibitory factor secreted by macrophages during inflammation and an inhibitor of the protein kinases that are upregulated in the CSF of individuals with cognitive impairment.

The other recent study also used SELDI to identify increases in chitinase 3-like 1 (CHI3L1, also known as HCgp39 and YKL-40) in the CSF as a biomarker of SIVE/ HIV encephalitis (HIVE) [56]. Microglia and macrophages were found to produce CHI3L1. It displaced extracellular matrix-bound basic fibroblast growth factor and inhibited the mitogenic activity of its receptor. This may contribute to neurodegeneration through lack of ability of this growth factor, and possibly other factors bound to the extracellular matrix, to support neurons. Independent studies corroborate its upregulation. Our previous microarray studies of SIVE found increased levels of CHI3L1 mRNA in the brain [57], and in our CSF proteomics study [45] this protein was elevated in SIVE.

Proteomics has also been used to identify modifications of proteins in the CSF, providing clues to the pathogenesis of neuroAIDS; in particular, nitrosative/oxidative stress has been examined [58]. Levels of proteins modified by nitric oxide, nitrate and 3-nitrotyrosine (3-NT) were assessed in the CSF of 46 patients with HIV infection classified according to their neurocognitive status and whether they had a history of intravenous drug abuse. Although the levels of nitrates and nitrites were increased in individuals with HAD and a history of drug abuse, this did not reach significance. However, CSF from these individuals had significantly elevated levels of 3-NTmodified proteins [58]. Subsequent analysis by immunoprecipitation and LC-MS/MS identified lipocalin-type prostaglandin D synthase (L-PDGS), an enzyme involved in the prostaglandin biosynthesis pathway, to be one of the major 3-NT-modified proteins in the CSF of HAD individuals with a history of drug abuse. Prostaglandins, which regulate many physiological functions, have been suggested to be involved in the pathogenesis of HAD [59]. Further analysis by immunoassay revealed a significant reduction in the enzymatic activity of L-PDGS, a reduction that was due to 3 -NT modification. This correlation with HAD may be functionally important, suggesting that L-PDGS is a potential biomarker for neuroAIDS in this population.

\section{Plasma biomarkers for neuroAIDS}

Although CSF is ideal for neuroproteomics, its relative unavailability and the limited amount of protein it contains makes such studies difficult . By contrast, blood plasma is a much more accessible biofluid and can contain markers relevant for prediction, diagnosis and/or further investigation into the cause and effects of neurological disorders. Despite the ease of obtaining plasma, a major challenge associated with its analysis is that it has a highly complex proteome, similar to that of CSF. The relatively high expression of abundant proteins such as serum albumin and immunoglobulins, which together constitute more than $85 \%$ of the total protein content, masks the less abundant proteins, which could be biomarkers.

Another necessary and informative step in protein biomarker discovery is to detect quantitative alterations of a protein in different disease and control conditions. Development of new quantitative proteomics approaches has greatly enhanced proteomics technologies. One of these, already mentioned above, relies on identifying the different levels of intact proteins separated by electrophoresis followed by protein identification by MS. An alternative strategy is to identify all proteins in a sample by MS and use data from the MS for quantification. Label-free methods such as used in [45] are possible, but chemical reactions to introduce isotopic tags at specific functional groups on amino acids have also been found to provide excellent methods of quantification. One such method is known as isobaric tag for relative and absolute quantitation (iTRAQ) [60]. In an iTRAQ experiment, different samples from control and experimental groups are labeled with different tags and up to eight conditions can be assessed simultaneously.

Using such a platform, afamin, a member of the albumin superfamily [61], was recently found by our group to be significantly downregulated after SIV infection only when CNS disease was developing [62]. Another study using 2D-DIGE-based MS [63] also found afamin to be downregulated (by 2.25-fold [63] compared with 2.77-fold [62]) when comparing HIV-infected individuals with dementia and those without CNS disease. Afamin has been shown to be a specific binding protein for vitamin E [64]. The central role of vitamin E, which comprises eight related tocopherols and tocotrienols, is to maintain physiological cellular and tissue function through the antioxidant properties of these compounds. Further analysis of $\alpha$-tocopherol $(\alpha \mathrm{TocH})$ levels in the plasma samples of monkeys with SIVE revealed decreases, but to varying extents [62]. However, an identical result was found in animals that did not develop CNS disease. Thus, the decrease in $\alpha \mathrm{TocH}$ correlated with infection itself and not the development of CNS disease, in contrast to afamin, which was 
decreased only in the animals that developed CNS disease.

Another potential biomarker was identified from our earlier gene expression analysis on SIVE rhesus brains [57]. Osteopontin (OPN; also known as secreted phosphoprotein 1, SPP1) is an extracellular protein important in regulating differentiation, immune cell activation and cell attachment and migration [65]. Subsequent studies revealed that OPN increased retention of monocytes and their protection from apoptosis [66], suggesting an underlying mechanism of macrophage accumulation during HIV/SIV infection. An enzymelinked immunosorbent assay (ELISA) revealed an increase of OPN in the CSF of HIV-infected individuals $[66,67]$. However, there was no difference in OPN CSF levels between HIV-infected individuals with neurocognitive disorders and those without such disorders. In plasma, however, ELISA analyses revealed a sequential increase in OPN across different diagnostic categories of HIV-associated neurocognitive disorders. We also found that expression of one of the receptors for OPN, a splice variant form of CD44 (CD44v6), is increased at early time points on monocytes in monkeys that will develop SIVE [68]. From a therapeutic standpoint, lowering OPN levels or its signaling is one possible strategy to ameliorate neuroAIDS.

\section{Organelle proteomics}

Although profiling of biofluids such as CSF and plasma have been useful, the ability to analyze the brain itself is key. A recent study using classical biochemical fractionation isolated synaptosomes (a subcellular fraction of nerve terminals and the synaptic region) from 19 human post-mortem specimens from uninfected and HIVinfected individuals classified by viral RNA load and immunoproteasome (IPS) concentrations as low HIV/ low IPS and high HIV/high IPS, of which the latter group had four individuals with HIVE [69]. Using twodimensional polyacrylamide gel electrophoresis (2DPAGE) and matrix-assisted laser desorption ionization time-of-flight MS, the authors [69] identified potentially functionally important alterations in synaptic proteins, such as synapsin $1 \mathrm{~b}$ (SYN1), which was downregulated in individuals with high HIV loads. SYN1 is a phosphoprotein protein present primarily in the presynaptic terminals that regulates synaptic vesicle pools bound to cytoskeletal proteins and modulates neurotransmitter release in response to a stimulus [70]. The decrease in its expression with HIV-1 infection suggests that there is abnormal regulation of the reserve pool of vesicles and thus abnormal neurotransmission. In addition, two proteins belonging to the 14-3-3 family (14-3-3 $\zeta$ and 14-3-3e), which are crucial for regulation of neuronal processes, including synaptic plasticity, were increased in individuals with high HIV loads. These isoforms have been previously reported to be increased in the CSF of patients with HIV/AIDS, primarily those with HAD [71,72]. The CSF of SIV-infected monkeys also showed higher expression of 14-3-3 proteins in animals with CNS disease [73].

In addition, changes in proteasomal proteins were found [69]. One proteasomal subunit protein, LMP7, was increased in individuals with high HIV loads, increasing the evidence that disruption of this process is linked to HIV-associated neurodegeneration. To determine whether the altered synaptosomal proteins in HIV/AIDS are histologically related to immunoproteasomal subunits, confocal microscopy was performed, showing co-expression of LMP7 and 14-3-3 $\zeta$ in punctate neuronal and neuropil markings in brains with high HIV loads [69]. Taken together, these findings [69-72] reflect changes in the synaptodendritic arbor, which have been documented during high HIV loads in the brain [74], and give important insights into how HIV can affect neurons in the brain while not infecting them.

\section{The scope of metabolomics}

The use of proteomics to study neuroAIDS has been well documented. Another high-throughput methodology, metabolomics, quantifies all low molecular weight endogenous metabolites in specified cellular, tissue or biofluid compartments and has seen increasing development and use. The measurement of metabolites is fundamental to every aspect of biology, from basic biochemistry to standard tests in clinical medicine. Although high-density data gathering metabolomics technologies are still under development, this methodology may soon become superior to other postgenomic technologies for pattern-recognition analyses of biological samples. A recent review [75] describes the translation of important metabolomics findings on neurological disorders to the clinic. Although early on this field centered around toxicological profiling and inborn errors of metabolism, recent applications have been extended to biomarker discovery, including for neurodegenerative disorders (reviewed in [76]).

Earlier targeted studies had identified changes in specific metabolite levels in CSF. For example, quinolinic acid, part of the kynurenine pathway, was shown to increase in CSF during HIV and SIV infection [77,78]. Similarly, the nitric oxide metabolites nitrate and nitrite were increased in a similar manner in the CSF $[26,79,80]$. Although these studies used a directed approach, our group has used a global MS-based metabolomics approach to identify differentially regulated metabolites in the CSF of monkeys before and after infection with SIV [81]. We found various metabolites to be upregulated, including carnitine, acyl-carnitines, fatty acids 
(linoleic, palmitic and stearic acids) and phospholipid molecules [81]. In conjunction with gene array analysis, the increase in free fatty acids and lysophospholipids was found to correlate with increased expression of specific phospholipases, PLA1A and PLA2G4C; PLA2G4C can release numerous identified fatty acids. Further, in situ hybridization experiments revealed increased expression of PLA2G4C in monkeys with SIVE. Identification of specific metabolites as well as mechanisms of their increase greatly add to the credibility and potential of MS-based metabolomics and demonstrates its power to identify potential markers for neuroAIDS.

\section{Conclusions}

The potential of post-genomic strategies has increased immensely in recent years. In the case of neuroAIDS, proteomics has revealed signs of immune system activation and protective responses. These have added to the clues provided by earlier gene array studies and, importantly, they provide molecules that can be assessed in biofluids in future studies. Proteomics has also identified post-translational modifications that affect protein function. Although proteins carry out most biological events in a cell, the chemical transformations catalyzed by enzymes lead to metabolites that themselves have important physiological roles. In addition to metabolic functions, such metabolic products mediate crucial interneuronal communications in the brain. Combining metabolomics with gene array studies in neuroAIDS has led to discovery of a pathogenic process: phospholipase activation involving an increase in specific lipids in the CNS. This helps to illustrate that although each of these approaches is crucial, long-term success will most certainly depend on integrating them. Additional developments and work in proteomics and metabolomics will enable a better understanding of the physiological alterations leading to disease, as well as providing additional biomarkers for diagnosis and therapeutic intervention.

\section{Abbreviations \\ 2D-DIGE, two-dimensional difference gel electrophoresis; 3-NT, 3-nitrotyrosine; AIDS, acquired immunodeficiency syndrome; CART, combined antiretroviral therapy; CHI3L1, chitinase 3-like 1; CNS, central nervous system; CSF, cerebrospinal fluid; ELISA, enzyme-linked immunosorbent assay; HIV, human immunodeficiency virus; HIVE, HIV encephalitis; IPS, immunoproteasome; iTRAQ, isobaric tag for relative and absolute quantitation; L-PDGS, lipocalin-type prostaglandin D synthase; MS, mass spectrometry; OPN, osteopontin; SELDI, surface enhanced laser desorption ionization; SIV, simian immunodeficiency virus; SIVE, SIV encephalitis; SOD1, soluble superoxide dismutase; SYN1, synapsin 1 b. \\ Competing interests \\ The authors declare that they have no competing interests.}

Authors' contributions

Both authors contributed equally to the preparation of this manuscript.

\section{Authors information}

GP is an Instructor in the Department of Pharmacology and Experimental Neuroscience at the University of Nebraska Medical Center. HSF is Professor and Executive Vice Chair of Faculty Development in the Department of Pharmacology and Experimental Neuroscience and Director of the Center for Integrative and Translational Neuroscience at the University of Nebraska Medical Center.

\section{Acknowledgements}

This is manuscript \#08 from the UNMC Center for Integrative and Translational Neuroscience. Our work is supported by NIH grants P30 MH062261, R01 MH073490 and P01 DA026146. We thank Robin Taylor (UNMC) for editing assistance.

Published: 30 March 2010

\section{References}

1. Ong EL: Common AIDS-associated opportunistic infections. Clin Med 2008, 8:539-543.

2. Yadav A, Collman RG: CNS inflammation and macrophage/microglial biology associated with HIV-1 infection. J Neuroimmune Pharmacol 2009 4:430-447.

3. Antinori A, Arendt G, Becker JT, Brew BJ, Byrd DA, Cherner M, Clifford DB, Cinque P, Epstein LG, Goodkin K, Gisslen M, Grant I, Heaton RK, Joseph J, Marder K, Marra CM, MCArthur JC, Nunn M, Price RW, Pulliam L, Robertson KR, Sacktor N, Valcour V, Wojna VE: Updated research nosology for HIVassociated neurocognitive disorders. Neurology 2007, 69:1789-1799.

4. Cysique LA, Brew BJ: Neuropsychological functioning and antiretroviral treatment in HIV/AIDS: a review. Neuropsychol Rev 2009, 19:169-185.

5. Dore GJ, McDonald A, Li Y, Kaldor JM, Brew BJ: Marked improvement in survival following AIDS dementia complex in the era of highly active antiretroviral therapy. AIDS 2003, 17:1539-1545.

6. Sacktor N, McDermott MP, Marder K, Schifitto G, Selnes OA, McArthur JC, Stern Y, Albert S, Palumbo D, Kieburtz K, De Marcaida JA, Cohen B, Epstein L: HIV-associated cognitive impairment before and after the advent of combination therapy. J Neuroviro/ 2002, 8:136-142.

7. Woods SP, Moore DJ, Weber E, Grant I: Cognitive neuropsychology of HIV-associated neurocognitive disorders. Neuropsychol Rev 2009, 19:152-168

8. Grant I: Neurocognitive disturbances in HIV. Int Rev Psychiatry 2008, 20:33-47.

9. Everall I, Vaida F, Khanlou N, Lazzaretto D, Achim C, Letendre S, Moore D, Ellis R, Cherner M, Gelman B, Morgello S, Singer E, Grant I, Masliah E: Cliniconeuropathologic correlates of human immunodeficiency virus in the era of antiretroviral therapy. J Neurovirol 2009, 15:360-370.

10. Achmat $Z$, Simcock J: Combining prevention, treatment and care: lessons from South Africa. AIDS 2007, 21 Suppl 4:S11-S20.

11. Aracena-Genao B, Navarro JO, Lamadrid-Figueroa H, Forsythe S, Trejo-Valdivia B: Costs and benefits of HAART for patients with HIV in a public hospital in Mexico. AIDS 2008, 22 Suppl 1:S141-S148.

12. Battegay M, Elzi L: Morbidity and mortality in HIV-infected individuals - a shift towards comorbidities. Swiss Med Wkly 2009, 139:564-570.

13. Blankson JN: Viral reservoirs and HIV-specific immunity. Curr Opin HIV AIDS 2006, 1:147-151.

14. Kiertiburanakul S, Sungkanuparph S: Emerging of HIV drug resistance: epidemiology, diagnosis, treatment and prevention. Curr HIV Res 2009, 7:273-278.

15. Krusi A, Wood E, Montaner J, Kerr T: Social and structural determinants of HAART access and adherence among injection drug users. Int J Drug Policy, 21:4-9.

16. Cabral GA: Drugs of abuse, immune modulation, and AIDS. J Neuroimmune Pharmacol 2006, 1:280-295.

17. Cohen GM: Access to diagnostics in support of HIV/AIDS and tuberculosis treatment in developing countries. AIDS 2007, 21 Suppl 4:S81-S87.

18. Kraft-Terry SD, Buch SJ, Fox HS, Gendelman HE: A coat of many colors: neuroimmune crosstalk in human immunodeficiency virus infection. Neuron 2009, 64:133-145.

19. Kraft-Terry SD, Stothert AR, Buch S, Gendelman HE: HIV-1 neuroimmunity in the era of antiretroviral therapy. Neurobiol Dis 2010, 37:542-548.

20. Davis LE, Hjelle BL, Miller VE, Palmer DL, Llewellyn AL, Merlin TL, Young SA, 
Mills RG, Wachsman W, Wiley CA: Early viral brain invasion in iatrogenic human immunodeficiency virus infection. Neurology 1992, 42:1736-1739.

21. Gendelman HE, Lipton SA, Tardieu M, Bukrinsky MI, Nottet HS: The neuropathogenesis of HIV-1 infection. J Leukoc Biol 1994, 56:389-398.

22. Gray F, Hurtrel M, Hurtrel B: Early central nervous system changes in human immunodeficiency virus (HIV)-infection. Neuropathol Appl Neurobiol 1993, 19:3-9.

23. Kaul M, Garden GA, Lipton SA: Pathways to neuronal injury and apoptosis in HIV-associated dementia. Nature 2001, 410:988-994.

24. Diesing TS, Swindells S, Gelbard H, Gendelman HE: HIV-1-associated dementia: a basic science and clinical perspective. AIDS Read 2002, 12:358-368.

25. Gartner S: HIV infection and dementia. Science 2000, 287:602-604

26. Lane TE, Buchmeier MJ, Watry DD, Fox HS: Expression of inflammatory cytokines and inducible nitric oxide synthase in brains of SIV-infected rhesus monkeys: applications to HIV- induced central nervous system disease. Mol Med 1996, 2:27-37.

27. Nuovo GJ, Alfieri ML: AIDS dementia is associated with massive, activated HIV-1 infection and concomitant expression of several cytokines. Mol Med 1996, 2:358-366.

28. Sharer LR: Pathology of HIV-1 infection of the central nervous system. A review. J Neuropathol Exp Neurol 1992, 51:3-11.

29. Marcondes MC, Burudi EM, Huitron-Resendiz S, Sanchez-Alavez M, Watry D, Zandonatti M, Henriksen SJ, Fox HS: Highly activated CD8(+) T cells in the brain correlate with early central nervous system dysfunction in simian immunodeficiency virus infection. J Immunol 2001, 167:5429-5438.

30. Roberts ES, Huitron-Resendiz S, Taffe MA, Marcondes MC, Flynn CT, Lanigan CM, Hammond JA, Head SR, Henriksen SJ, Fox HS: Host response and dysfunction in the CNS during chronic simian immunodeficiency virus infection. J Neurosci 2006, 26:4577-4585

31. Burudi EM, Fox HS: Simian immunodeficiency virus model of HIV-induced central nervous system dysfunction. Adv Virus Res 2001, 56:435-468.

32. Fox HS: Virus-host interaction in the simian immunodeficiency virusinfected brain. J Neurovirol 2008, 14:286-291.

33. Fox HS, Gold LH, Henriksen SJ, Bloom FE: Simian immunodeficiency virus: a model for neuroAIDS. Neurobiol Dis 1997, 4:265-274.

34. Rausch DM, Murray EA, Eiden LE: The SIV-infected rhesus monkey model for HIV-associated dementia and implications for neurological diseases. J Leukoc Biol 1999, 65:466-474

35. Sharer LR, Baskin GB, Cho ES, Murphey-Corb M, Blumberg BM, Epstein LG: Comparison of simian immunodeficiency virus and human immunodeficiency virus encephalitides in the immature host. Ann Neurol 1988, 23 Suppl:S108-S112

36. Frank $\mathrm{R}$, Hargreaves $\mathrm{R}$ : Clinical biomarkers in drug discovery and development. Nat Rev Drug Discov 2003, 2:566-580.

37. Horning EC, Horning MG: Metabolic profiles: gas-phase methods for analysis of metabolites. Clin Chem 1971, 17:802-809.

38. Simonsen AH, McGuire J, Hansson O, Zetterberg H, Podust VN, Davies HA, Waldemar G, Minthon L, Blennow K: Novel panel of cerebrospinal fluid biomarkers for the prediction of progression to Alzheimer dementia in patients with mild cognitive impairment. Arch Neuro/ 2007, 64:366-370.

39. Simonsen AH, McGuire J, Podust VN, Davies H, Minthon L, Skoog I, Andreasen $\mathrm{N}$, Wallin A, Waldemar G, Blennow K: Identification of a novel panel of cerebrospinal fluid biomarkers for Alzheimer's disease. Neurobiol Aging 2008, 29:961-968.

40. Thompson EJ: Cerebrospinal fluid. J Neurol Neurosurg Psychiatry 1995 59:349-357

41. Kanekiyo T, Ban T, Aritake K, Huang ZL, Qu WM, Okazaki I, Mohri I, Murayama S, Ozono K, Taniike M, Goto Y, Urade Y: Lipocalin-type prostaglandin D synthase/beta-trace is a major amyloid beta-chaperone in human cerebrospinal fluid. Proc Natl Acad Sci USA 2007, 104:6412-6417.

42. Thouvenot $E$, Urbach S, Dantec C, Poncet J, Seveno M, Demettre E, Jouin P, Touchon J, Bockaert J, Marin P: Enhanced detection of CNS cell secretome in plasma protein-depleted cerebrospinal fluid. J Proteome Res 2008, 7:4409-4421.

43. Pan S, Zhu D, Quinn JF, Peskind ER, Montine TJ, Lin B, Goodlett DR, Taylor G, Eng J, Zhang J: A combined dataset of human cerebrospinal fluid proteins identified by multi-dimensional chromatography and tandem mass spectrometry. Proteomics 2007, 7:469-473.

44. Rozek W, Ricardo-Dukelow M, Holloway S, Gendelman HE, Wojna V, Melendez LM, Ciborowski P: Cerebrospinal fluid proteomic profiling of HIV-1-infected patients with cognitive impairment. J Proteome Res 2007, 6:4189-4199.

45. Pendyala G, Trauger SA, Kalisiak E, Ellis RJ, Siuzdak G, Fox HS: Cerebrospinal fluid proteomics reveals potential pathogenic changes in the brains of SIV-infected monkeys. J Proteome Res 2009, 8:2253-2260.

46. Speth C, Williams K, Hagleitner M, Westmoreland S, Rambach G, Mohsenipour I, Schmitz J, Wurzner R, Lass-Florl C, Stoiber H, Dierich MP, Maier H: Complement synthesis and activation in the brain of SIV-infected monkeys. J Neuroimmunol 2004, 151:45-54

47. Morgan BP, Gasque P, Singhrao S, Piddlesden SJ: The role of complement in disorders of the nervous system. Immunopharmacology 1997, 38:43-50

48. Nolte C, Moller T, Walter T, Kettenmann H: Complement 5a controls motility of murine microglial cells in vitro via activation of an inhibitory G-protein and the rearrangement of the actin cytoskeleton. Neuroscience 1996, 73:1091-1107.

49. Osaka H, Mukherjee P, Aisen PS, Pasinetti GM: Complement-derived anaphylatoxin C5a protects against glutamate-mediated neurotoxicity. J Cell Biochem 1999, 73:303-311.

50. Boos L, Szalai AJ, Barnum SR: C3a expressed in the central nervous system protects against LPS-induced shock. Neurosci Lett 2005, 387:68-71.

51. Eikelenboom P, Hack CE, Rozemuller JM, Stam FC: Complement activation in amyloid plaques in Alzheimer's dementia. Virchows Arch B Cell Pathol Ind Mol Pathol 1989, 56:259-262.

52. Veerhuis R, Janssen I, Hack CE, Eikelenboom P: Early complement components in Alzheimer's disease brains. Acta Neuropathol 1996, 91:53-60.

53. Yasojima K, Schwab C, McGeer EG, McGeer PL: Up-regulated production and activation of the complement system in Alzheimer's disease brain. Am J Pathol 1999, 154:927-936.

54. Gasque P, Neal JW, Singhrao SK, McGreal EP, Dean YD, Van BJ, Morgan BP: Roles of the complement system in human neurodegenerative disorders: pro-inflammatory and tissue remodeling activities. Mol Neurobio/ 2002, 25:1-17

55. Laspiur JP, Anderson ER, Ciborowski P, Wojna V, Rozek W, Duan F, Mayo R, Rodriguez E, Plaud-Valentin M, Rodriguez-Orengo J, Gendelman HE, Melendez LM: CSF proteomic fingerprints for HIV-associated cognitive impairment. J Neuroimmunol 2007, 192:157-170.

56. Bonneh-Barkay D, Bissel SJ, Wang G, Fish KN, Nicholl GC, Darko SW, MedinaFlores R, Murphey-Corb M, Rajakumar PA, Nyaundi J, Mellors JW, Bowser R, Wiley CA: YKL-40, a marker of simian immunodeficiency virus encephalitis, modulates the biological activity of basic fibroblast growth factor. Am J Pathol 2008, 173:130-143.

57. Roberts ES, Zandonatti MA, Watry DD, Madden L, Henriksen SJ, Taffe MA, Fox HS: Induction of pathogenic sets of genes in macrophages and neurons in neuroAIDS. Am J Patho/ 2003, 162:2041-2057

58. Li W, Malpica-Llanos TM, Gundry R, Cotter RJ, Sacktor N, McArthur J, Nath A: Nitrosative stress with HIV dementia causes decreased L-prostaglandin D synthase activity. Neurology 2008, 70:1753-1762.

59. Griffin DE, Wesselingh SL, McArthur JC: Elevated central nervous system prostaglandins in human immunodeficiency virus-associated dementia. Ann Neurol 1994, 35:592-597.

60. Ross PL, Huang YN, Marchese JN, Williamson B, Parker K, Hattan S, Khainovsk N, Pillai S, Dey S, Daniels S, Purkayastha S, Juhasz P, Martin S, Bartlet-Jones M, He F, Jacobson A, Pappin DJ: Multiplexed protein quantitation in Saccharomyces cerevisiae using amine-reactive isobaric tagging reagents. Mol Cell Proteomics 2004, 3:1154-1169.

61. Lichenstein HS, Lyons DE, Wurfel MM, Johnson DA, McGinley MD, Leidli JC, Trollinger DB, Mayer JP, Wright SD, Zukowski MM: Afamin is a new member of the albumin, alpha-fetoprotein, and vitamin D-binding protein gene family. J Biol Chem 1994, 269:18149-18154.

62. Pendyala G, Trauger SA, Siuzdak G, Fox HS: Quantitative plasma proteomic profiling identifies the vitamin $\mathrm{E}$ binding protein afamin as a potential pathogenic factor in SIV induced CNS disease. J Proteome Res, 9:352-358.

63. RozekW. Horning J, Anderson J, Ciborowski P: Sera proteomic biomarker profiling in HIV-1 infected subjects with cognitive impairment. Proteomics Clin App/2008, 2:1498-1507.

64. Jerkovic L, Voegele AF, Chwatal S, Kronenberg F, Radcliffe CM, Wormald MR, Lobentanz EM, Ezeh B, Eller P, Dejori N, Dieplinger B, Lottspeich F, Sattler W, Uhr M, Mechtler K, Dwek RA, Rudd PM, Baier G, Dieplinger H: Afamin is a novel human vitamin E-binding glycoprotein characterization and in vitro expression. J Proteome Res 2005, 4:889-899.

65. Lin YH, Yang-Yen HF: The osteopontin-CD44 survival signal involves activation of the phosphatidylinositol 3-kinase/Akt signaling pathway. 
J Biol Chem 2001, 276:46024-46030.

66. Burdo TH, Wood MR, Fox HS: Osteopontin prevents monocyte recirculation and apoptosis. J Leukoc Biol 2007, 81:1504-1511.

67. Burdo TH, Ellis RJ, Fox HS: Osteopontin is increased in HIV-associated dementia. J Infect Dis 2008, 198:715-722.

68. Marcondes MC, Lanigan CM, Burdo TH, Watry DD, Fox HS: Increased expression of monocyte CD44v6 correlates with the development of encephalitis in rhesus macaques infected with simian immunodeficiency virus. J Infect Dis 2008, 197:1567-1576.

69. Gelman BB, Nguyen TP: Synaptic proteins linked to HIV-1 infection and immunoproteasome induction: proteomic analysis of human synaptosomes. J Neuroimmune Pharmacol 2010, 5:92-102.

70. Evergren E, Benfenati F, Shupliakov O: The synapsin cycle: a view from the synaptic endocytic zone. J Neurosci Res 2007, 85:2648-2656.

71. Miller RF, Green AJ, Giovannoni G, Thompson EJ: Detection of 14-3-3 brain protein in cerebrospinal fluid of HIV infected patients. Sex Transm Infect 2000, 76:408

72. Wakabayashi H, Yano M, Tachikawa N, Oka S, Maeda M, Kido H: Increased concentrations of 14-3-3 epsilon, gamma and zeta isoforms in cerebrospinal fluid of AIDS patients with neuronal destruction. Clin Chim Acta 2001, 312:97-105.

73. Helke KL, Queen SE, Tarwater PM, Turchan-Cholewo J, Nath A, Zink MC, Irani DN, Mankowski JL: 14-3-3 protein in CSF: an early predictor of SIV CNS disease. J Neuropathol Exp Neurol 2005, 64:202-208

74. Masliah E, Heaton RK, Marcotte TD, Ellis RJ, Wiley CA, Mallory M, Achim CL, McCutchan JA, Nelson JA, Atkinson JH, Grant I: Dendritic injury is a pathological substrate for human immunodeficiency virus-related cognitive disorders. Ann Neurol 1997, 42:963-972.

75. Nordstrom A, Lewensohn R: Metabolomics: moving to the clinic. J Neuroimmune Pharmacol 2010, 5:4-17.
76. Pendyala G, Want EJ, Webb W, Siuzdak G, Fox HS: Biomarkers for neuroAIDS: the widening scope of metabolomics. J Neuroimmune Pharmacol 2007 2:72-80

77. Heyes MP, Brew BJ, Martin A, Price RW, Salazar AM, Sidtis JJ, Yergey JA, Mouradian MM, Sadler AE, Keilp J: Quinolinic acid in cerebrospinal fluid and serum in HIV-1 infection: relationship to clinical and neurological status. Ann Neurol 1991, 29:202-209.

78. Heyes MP, Jordan EK, Lee K, Saito K, Frank JA, Snoy PJ, Markey SP, Gravell M: Relationship of neurologic status in macaques infected with the simian immunodeficiency virus to cerebrospinal fluid quinolinic acid and kynurenic acid. Brain Res 1992, 570:237-250.

79. Giovannoni G, Miller RF, Heales SJ, Land JM, Harrison MJ, Thompson EJ. Elevated cerebrospinal fluid and serum nitrate and nitrite levels in patients with central nervous system complications of HIV-1 infection: a correlation with blood-brain-barrier dysfunction. J Neurol Sci 1998, 156:53-58.

80. Svenningsson A, Petersson AS, Andersen O, Hansson GK: Nitric oxide metabolites in CSF of patients with MS are related to clinical disease course. Neurology 1999, 53:1880-1882.

81. WikoffWR, Pendyala G, Siuzdak G, Fox HS: Metabolomic analysis of the cerebrospinal fluid reveals changes in phospholipase expression in the CNS of SIV-infected macaques. J Clin Invest 2008, 118:2661-2669.

doi:10.1186/gm143

Cite this article as: Pendyala G, Fox HS: Proteomic and metabolomic strategies to investigate HIV-associated neurocognitive disorders. Genome Medicine 2010, 2:22. 